\title{
An Analysis of Prepositional Phrase Used in Thesis at Graduate Program of Universitas Negeri Padang
}

\author{
Yuli Eka Putri ${ }^{1}$, Hermawati Syarif ${ }^{2}$, and Refnaldi ${ }^{3}$ \\ ${ }^{1}$ State University of Padang, Padang, Indonesia putryyyuly@ gmail.com \\ ${ }^{2}$ State University of Padang, Padang, Indonesia hermawati_sy@yahoo.com \\ ${ }^{3}$ State University of Padang, Padang, Indonesia refnaldi@yahoo.com
}

\begin{abstract}
The principal purpose of this article was to present the types of prepositional phrase structure are mostly found on students' Thesis in Graduate Program at Universitas Negeri Padang. The method used in this research was descriptive. The source of the data for this research was the review of related literature of thesis written by English Education students. The researcher used sampling technique, the researcher was taken 10 Thesis as a sample in this research. The data were collected through coding sheet. The findings indicate that (1) the writers have used prepositional phrase in Thesis writing, (2) the writers have used several structure of prepositional phrases, however in the thesis writing, they still tend to use one of the prepositional phrase' structure, meanwhile there are other types of prepositional phrase structure.
\end{abstract}

Keywords: Writing, students' thesis, prepositional phrase

\section{INTRODUCTION}

In academic writing especially, students are required to make the sentences that are grammatically correct. It is because academic writing serves the accurate information and data that can be verified. At university level, the students have written many kinds of writing. For English Graduate students, the final writing task to get their degree at university is writing thesis. Thesis Writing is an important part of any college education program. Before students can obtain any degree in a university, they should have a passing grade in a thesis writing class. A thesis is an end product that students must write after attending several major courses accompanied with English courses.

In thesis writing, the use of preposition is important. They help to relate subject, object and verb sometimes to provide more information. Prepositions hold a privileged position as parts of speech in that they are a 'closed class'. In other words, they are a select group of words that don't accept new members to their club. While prepositions are limited in number, they are important because they act as vital markers to the structure of a sentence; they mark special relationships between persons, objects, and locations. For this reason, we should think carefully about how we incorporate the teaching and learning of prepositions into our classes.

Furthermore, preposition as functional words play an important role in the construction of phrases and sentences. They connect typically a noun or a pronoun to another word and show their relationships in a sentence. Instead of a prepositions work in combination with a noun or pronoun to create phrase that modify noun while prepositional phrase convey spatial, temporal or directional meaning. Based on Cindy (2005:36), identifies a prepositional phrase is a word expressing time, location or condition that is followed by a noun or pronoun.

Moreover, prepositional phrase is important part of a sentence. They help to relate subject, object and verb sometimes to provide more information. Prepositional phrases should generally be placed near what they describe. Halliday (2000:51) states that prepositional phrase describes as consisting of a preposition phrase a nominal group. It means that, a prepositional phrases always begin with a preposition which always end with a noun or pronoun. Thus, prepositional phrase is a group of words consisting of a preposition, its object, and any words that modify the object. It is only a portion of a sentence and cannot stand on its own as a complete thought.

Furthermore, prepositional phrases have syntactic functions in sentences, that is the grammatical relationship of one constituent to another within a syntactic construction. Syntactic functions of prepositional phrase plays an integral role to express the meaning which is related to the meaning expressed by adverbs and adjectives: where, when, how and what kind. It can also express a sense of why or who. Hofmann (1993:159) states that the importance of prepositions is reflected in the description associated with the English language, as being a prepositional language. According to Downing and Locke (2006:534) preposition is divided into two groups. 1) Simple preposition. Preposition consists of a single prepositional particle. Here are the word lists as single prepositional particles.2) Complex preposition.

However, other elements prepositional phrase is noun phrase. prepositional phrase contains from 
preposition which is complemented by noun phrase. noun phrases are syntactic structures with a head noun $(\mathrm{HN})$ or its complements as its focus. Downing and Locke (2006:536) classified the prepositional complements include Noun Phrases (NP), Noun Phrase (Wh-Clauses), Noun phrase (Ing-Clauses). Furthermore, prepositional phrases mostly consist of a preposition followed by a noun phrase, known as prepositional complement. The preposition can be thought of as a link relating the noun phrase to preceding structures. As the prepositional complement, noun phrase is a head complement relation. It is supported by Burton (2011: 146) states that noun phrase is a head - complement relation which is linked by a preposition.

Based on the explanation above, it can be concluded that prepositional phrases are cohesive word groups forming syntactic units, consisting of a preposition plus a noun phrase as complemented of the preposition. Although of a prepositional phrases are more significant than the preposition that introduces it, which generally has little meaning. A preposition cannot normally occur without a nominal unit, and a nominal unit is not part of a prepositional phrase if there is no preposition. Both of them are equally necessary to form the phrase; both have equal grammatical status. Moreover, prepositional phrase is a group of words which consists of two or more words but does not have a subject or predicate and functions to take a complete add the meaning or information of the sentences. The words in a prepositional phrase act together so that the phrase itself functions as a single part of speech.

\section{METHOD}

The type of this research was a qualitative research since it was going to seek deep discussion about the prepositional phrase used in the review of related literature of students' Thesis. The research was conducted at Universitas Negeri Padang, Padang Sumatera Barat. The source of the data for this research was the review of related literature of thesis written by English Education students. The instruments that used in this research were coding sheet and coding sheet notes. The coding sheet made in terms of code followed by the information about the content and function words as well as the structure of prepositional phrase based on the theory suggested by Downing and Locke (2006:536). Then, it was analyzed by using the technique suggested by Gay and Airasian (2000:240).

The data analysis in this research was begun by analyzing the data from the documents; coding sheet and coding sheet notes. In analyzing the data from document the researcher begun by observing the students' review of related literature chapter. After that, the researcher coded those structures of prepositional phrase that used by writers. The researchers observed the structure of prepositional phrase used in the review of related literature chapter. After observing the differentiation, the researcher marked the types of prepositionla phrase structures into coding sheet notes. In the next process, the researcher typed all the types of structures of prepositional phrase that were found in the review of related literature chapter of students' thesis and classified them into types of prepositional phrases' structure. At last, the researcher displayed the data and drawn the conclusion on the most dominant and secondary structures of prepositional phrase found in the review of related literature chapter on students' thesis based on the documents.

\section{RESULT AND DISCUSSION}

Based on the data analysis, it was found that all of the 10 documents state this first indicator. According to Downing and Locke's theory all of them used prepositional phrase as one of important aspect in connecting their ideas into statements at the concluding paragraph in the review of related literature chapter. The structures of prepositional phrase that were found in the documents included structure of the prepositional phrase. The first one is sub indicator 1.a structure of preposition in which the writer used simple preposition and complex preposition. The second one is 1.b the structure of its noun phrase in which the structure of noun phrase that has been followed by a preposition which is called as prepositional phrase. in this case, the structure of its noun phrase include into three forms such as preposition +noun, preposition +wh-clause, and preposition + ing clause.

The data show that all of the writer used prepositional phrase in concluding their ideas. The first structure of prepositional phrase found in the data is the structure of preposition (S.1.a). It found that all the writers used sub indicator 1. a structure of preposition in making sentences for all of the concluding paragraphs at the review of related literature chapter.

For instance, a statement of "Based on the experts' definition above......" was found in the beginning of introduction in concluding paragraph Document 1 (D1). The phrase above obviously shows the prepositional phrase in expressing the writers' idea. The prepositional phrase included simple preposition on and above. There were some prepositions that were identified on and above in which both of them belongs to simple preposition. The structure of preposition S1.a(a) was also found in the beginning of the introduction section of concluding paragraph in Document 2 (D2) stating "from the table above...." like the first example, the statement of the topic in Document 25 is begun by a prepositional phrase in which the structure was simple preposition initially. From the prepositional phrase above from belongs to simple preposition

The two samples above indicate the importance of prepositional phrase in expressing the writers' idea and also to connect each phrase into a sentence in concluding paragraph. On the other hand, the following are the examples of phenonena prepositional phrase that include simple preposition:

\footnotetext{
"......of reading comprehension” (Document 3 )

“.... in the process of teaching speaking....." (document 4)

"... about the authentic assessment...." (Document 5)

"....with affective component..." (Document 6)

“....on the explanation...” (Document 8 )
} 
“...by teachers...” (Document 9)

It can be seen that prepositional phrase was contained by simple preposition was of, in, about, with, on and by. Based on data analysis, there is a strong tendency for the writers to use phenomena prepositional phrase that has structured simple preposition to connect the phrases into sentences. All of them used simple preposition as the structure of prepositional phrase. It is stated by all the prepositional phrase at the concluding paragraph include simple preposition. In other words, for the prepositional phrase's structure S1. a(a) was stated more than 1 times in the whole of concluding paragraphs in the review of related literature chapter. The repetition of simple preposition S1a (a) is found mostly in each paragraphs. As displayed in the Appendix, it can be seen that almost all of the documents contain more than one Step 1.a (a)

The enormous prepositional phrase which included of simple preposition S 1.a (a) can be found in Document 7. In which the total of prepositional phrase's structure with simple preposition was found 114 simple prepositions for the total paragraph is 8 paragraphs. Here is the description of how the writer reviews previous researches and then include prepositional phrase.

\section{“....by using anticipation strategy” (Document 7)}

It can be seen that the writer introduces previous studies to accentuate that the research topic chosen simple preposition as the part of prepositional phrase in the concluding paragraphs. In this case, each document has 7 until 11 concluding paragraphs in the review of related literature chapter. Prepositional phrase is found almost in all of the paragraphs. It is done by stating that some previous researchers had conducted similar reserach topic and then used their own statements by including prepositional phrase in it.

Unlike those samples above, the result of data analysis indicates the other structure of prepositional phrase was complex preposition S.1a (b). There are some complex prepositions S1. a (b) that were found almost in all of the documents. Meanwhile, complex preposition S.1.a(b) which are not established at the initial section of the concluding paragraphs at review of related literature chapter, however it stated in the middle of the sentences at concluding paragraph.

In some cases, the writers actually begin to introduces the previous studies with simple preposition, however the complex preposition was still found in the concluding paragraphs such as "....in line with " ( Document 1) and " ...because of their different characteristics...." (Document 3). The writer of Document 1 used in line within which it belongs to complex preposition. The similar case is also found in the Document 3 which used because of it belongs to complex preposition. Similarly, there was only one complex preposition that can be found in both of the documents. In this case, the tendency the writers to use complex preposition were not as much as simple preposition in concluding paragraph.
Similarly, complex preposition is also found in these documents:

"......in accordance with the assessment standards..." (Document 5)

".....as well as the other characteristics....." (Document 6)

"....in order to communicate certain message...." (Document 8)

".....in terms of the resources necessary...." (Document 9)

“...such as in pre teaching..." (Document 10)

Besides, there was only 1 out of the 10 writers who did not state S.1.a (b) (complex preposition). It is the writer of Document 4 . It can be seen that the writer tend to use more simple preposition than complex preposition in concluding the previous studies on the concluding paragraph in the review of related literature chapter. It is done by stating that some previous theory by had delivered their own ideas by having simple preposition as part of prepositional phrase in the sentences. Besides, the writer quotes the previous researchers' findings to show what has been found and who has found it. based on the data analysis, the identified structure of prepositional phrase in this case S. 1a ( structure of preposition) that mostly used in the review of related chapter is considered fairly written since it has found both of structure of prepositional that related to theory.

Furthermore, based on data analysis, it was found that the other structure of prepositional phrase was the structure of its noun phrase (S. 1. b). Based on the theory this structure has three kind of structures. First structure is prepositional phrase that contain a preposition and noun phrase / noun (preposition + noun phrase), it was indicated as $\mathrm{S}$. 1b (a). Then, next prepositional structure contain preposition and then followed by wh -clause (preposition+ wh-clause) as indicated S.1.b (b). And the last one is the prepositional structure contain preposition and it is followed by Ing clause (Preposition+ Ing-clause).

Based on data analysis, the noun phrase structure that supported prepositional phrase can be found in all of the documents. First, for the prepositional phrase structure (preposition+noun phrase / noun) S.1b(a) can be described as follow:

"the researcher is in line to define authentic assessment which concerns on aspects of students' knowledge, skills, and attitude that are used in a real world,....." (Document 5)

" in this research, to know the reading interest of the students, the researcher uses the indicators of reading interest proposed by Hidi (2001),..."(Document 3)

Based on data analysis, both of the documents stated the prepositional phrase which the structure was preposition+noun phrase S.1.b(a). The explanation for document 5. Related to sentences above, it can be found there are three prepositional phrases, those are on aspect is a prepositional phrase in which contain preposition on and aspects is as noun phrase (noun). Of students' knowledge is a prepositional phrase in which contain of as preposition 
and then it is followed by a noun phrase (noun) students' knowledge. The last one is in a real world, it is classified in as preposition and a real world as noun phrase. similarly, wiith document 3 . It is found that there are two prepositional phrases. In this research is a prepositional phrase that has structured by preposition in and the it is followed by a noun phrase this research. Of the students belongs to prepositional phrase in which of as the preposition and then the students as the noun phrase.

Moreover, there is a strong tendency for the writers to use this prepositional structure (Preposition+noun phrase) in the concluding paragraph. It found that all of the documents stated this structure. All of them use the prepositional phrase structure S.1b(a) as the current needs in creating sentences in expressing their ideas in the review of related literature chapter. The repetition is found mostly in all of the concluding paragraphs. As displayed in the Appendix ..., it can be seen that almost all of the documents contain more than one Step 1.a. The enormous repetition of Step 1.b (a) can be found in Document 10 .

Then, the writer continues to describe the preliminary study result (structure of prepositional phrase in which structure of its noun phrase which belong to S.1.b. Meanwhile, the prepositional structure which contain the noun phrase structured (Preposition+ whclause) S.1b (b). Typically, it can be found only in these two documents 8 and document 9 . It is stated in concluding paragraph no 3 and paragraph 5 . It can be seen in Document 3. Besides, for prepositional phrase with this structure can be found in the paragraph 1,6 , and 7 in the document 9 (see appendix ...).

"...indeed in all subject that needing to find out the students' comprehending about what they learn.... (concluding paragraph 3 ) document 8

"...students comprehend about what they teach..." (concluding paragraph paragraph 2) document 8

"... a way of how humans interact...." (concluding paragraph 1) document 9

"...of question about how the assessment task..." paragraph 6) document 9

"...about how performance on the assessment accurately..." paragraph 7) document 9

The samples above shows that the writer states the prepositional phrase with the structure of its noun phrase (Preosition + Wh-clause). For example, about what they learn (concluding paragraph 3 ) in document 8 . It can be identified about is the preposition and then it is folloed by a noun phrase with the structure (Wh-clause) what they learn. Next, about what they teach is a prepositional phrase contains about as preposition and then what they teach is identified as noun phrase (Wh-clause).

Furthermore, the third structure of its noun phrase of a prepositional phrase is (preposition + Ingclause) S.1 b (c). Prepositional phrase contain with a preposition and the its noun phrase structure in which the noun phrase form(ing clause). For example, the writer states S. 1.b (c) ( preposition +Ing-clause) firstly in first concluding paragraph . This type of prepositional phrase with this structure can be seen on all of the documents Document 1, Document 2 Document 3, Document 4, Document 5, Document 6, Document, Document 8, Document 9, Document 10. the representative example is taken from Document 7, Document 8, as follow (see Appendix ...):

“...in doing the process... (S. $1 . b$ (c), paragraph 1 Document 8)

“.. of reading comprehension test.... (S. $1 . \boldsymbol{b}(\boldsymbol{c})$, paragraph 2 Document 8 )

“...of teaching reading..." (S. $1 . b(c)$, paragraph 3 Document 8)

“...by using anticipation...” $S . \quad 1 . b(c)$, paragraph 6 Document 8)

“... about reading comprehension... (S. $1 . b(c)$, paragraph 11 Document 8 )

“...by expressing... (S. 1.b(c), paragraph 1 Document 9)

Document 9 )

The demand of using it... (S. 1.b(c), paragraph 3

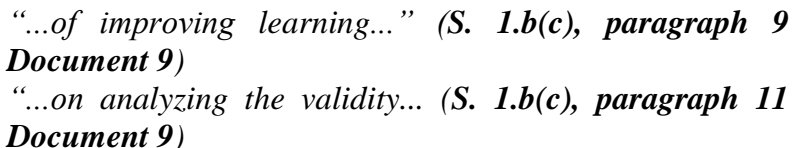

Both of the samples are the structure of its noun phrase in a prepositional phrase above shows that the writers use S.1. b(c) (Preposition+ Ing-clause) recurrently. It is written either in series of concluding paragraph in Document 8 or Document 9. The repetition of Step 1.a can be found in most of concluding paragraph in the review of related literature chapter in these documents. The sample above shows that the writer has established the structure of its noun phrase (Ing- clause) in a prepositional phrase S.1.b (c) in in the concluding paragraph in te review of related literature chapter. Nevertheless, the writer restates S.1.b after the gap has been described. In other words, for the first indicator structure that prepositional phrase mostly used in the review of related literature chapter has beed indicated.

To conclude, establishing the structure of prepositional phrase (S.1) has already been stated in all of the documents analyzed. It was found that from all 10 documents found of structure of prepositional phrase in their review of related literature on their Thesis. This indicator is established two steps; they are Step 1.a (structure of preposition) and Step 1.b (structure of its noun phrase). The data show that almost all of the writers state Step 1.a and Step 1.b, however, only one of them who does not find complex preposition in the document. Thus, it can be said that almost all of the documents' is written by providing the writers' statement by stating prepositional phrase structure. The data shown that the writer tend to use simple preposition S.1a (a), largely more than complex preposition S.1a( b) . Besides, for the noun phrase structure in prepositional phrase, it found that all of the structure of its noun phrase is found in all of the 
document although there are some of documents that do not find the structure of its noun phrase S. 1.b (b) preposition+ Wh clause. this structure is stated in two documents only; they are document 8 and document 9 . Furthermore, it was found that indicator for structure of prepositional phrase that has structured of its noun phrase S. 1.b (c) Preposition+ ing caluse. It is stated recurrently in almost all of the documents. It is repeated either in series of concluding paragraph for more than 5 prepositional phrase in a paragraph.

Furthermore, All the writers apply both of types structure of prepositional phrase in which, structure of preposition and the structure of its noun phrase. Furthermore, prepositional phrase contains by preposition and its followed by noun phrase, so that the structure of prepositional phrase is divided into structure of preposition and structure of its noun phrase. Thus, structure of preposition include simple preposition ( S.1a (a)) and complex preposition (s.1.b (b)).Referring to the data analysis, it found that all of the writers used both of these structure on their concluding paragraph in the review of related literature chapter. The writers used prepositional phrase in expressing their opinion or when they restate the previous studies or theory and then replace with their own statement in which they used prepositional phrase as the part of their sentences in the concluding paragraph.

Based on data analysis, most of step 1.a (a out of the 16 documents) is written too general or too broad area ( see appendix..). As indicated in some samples in the data description above, most of writers tend to begin writing the introduction by claiming the importance of language in society or the need to learn English as international language. As the consequences, the writers write some extra paragraphs to narrow down the ideas before they indicate the research problem.

Among the structures at the concluding paragraph of review of related literature chapter, it found that prepositional phrase has stated as the part of writers' opinion in stating their own opinions. It found that 765 words are simple prepositions, thus representing almost 96,3 percent of all the words in the corpus. Then, 29 words as complex preposition thus representing 3,65 percent. This result supports the claim held by Mindt and Weber (1989) that every eighth word in English is a preposition, and therefore, they can be thought of as important categories as far as the English language is concerned. While, the other of structures of prepositional phrase is the structure if its noun phrase. It found 630 words as prepositional phrase that has noun structure (Preposition+noun phrase) thus representing 3,65 percent. Then, it followed by the second structure that is prepositional phrase (preposition+ Wh clause) 12 words in which presenting 1,39 percent. The last structure of the noun phrase structure in prepositional phrase is (preposition + ing clause) 218 words that represents 25,3 percent.

This result can be seen as a "global probability", that is "pertaining to the language as a whole, in all contexts and registers" Halliday and Webster (2009:252) which means that they can be revealing of general characteristics of the English Language. However, these prepositions do not seem to be equally distributed in all of the documents, as shown in the following table

Table 1. Percentage of structure of prepositional phrases in the thesis

Table 1 presents those prepositions studied in the

\begin{tabular}{|c|c|c|c|c|c|c|c|c|}
\hline No. & Indicators & Sub Indicators & Stated & Total & Identi & atinntated & Total & $\%$ \\
\hline \multirow[t]{5}{*}{1.} & \multirow{2}{*}{$\begin{array}{l}\text { Structure of } \\
\text { prepositional phrase } \\
\text { a) Structure of } \\
\text { Preposition }\end{array}$} & $\begin{array}{ll}\text { a. } & \text { Simple } \\
& \text { preposition }\end{array}$ & $\sqrt{ }$ & 765 & 96,3 & - & - & 0 \\
\hline & & $\begin{array}{ll}\text { b. } & \text { Complex } \\
\text { preposition }\end{array}$ & $\sqrt{ }$ & 29 & 3,65 & - & - & 0 \\
\hline & \multirow[t]{3}{*}{$\begin{array}{l}\text { b) Structure of its } \\
\text { noun phrase }\end{array}$} & $\begin{array}{l}\text { a. } \\
\text { Prepositio } \\
\text { nal phrase } \\
\text { (prepositio } \\
\text { n -Noun } \\
\text { phrase) }\end{array}$ & $\sqrt{ }$ & 630 & 73,2 & - & - & 0 \\
\hline & & $\begin{array}{ll}\text { b. } & \text { Prepositio } \\
& \text { nal phrase } \\
& \text { (prepositio } \\
& n-\text { wh }- \\
& \text { clauses) }\end{array}$ & $\sqrt{ }$ & 12 & 1,39 & - & - & 0 \\
\hline & & $\begin{array}{ll}\text { c. } & \text { Prepositio } \\
\text { nal phrase } \\
\text { (prepositio } \\
\text { n - Ing } \\
\text { clauses) }\end{array}$ & $\sqrt{ }$ & 218 & 25,3 & - & - & 0 \\
\hline
\end{tabular}

documents, which actually seem to differ slightly from one sub-indicators to the other. Simple prepositions in 
this case can be seen as the most structured of prepositional phrase to express meaning and the opinion of the writer at concluding paragraph, while for the noun phrase structures is the first sub indicator that is prepositional phrase that included preposition+noun phrase (noun).

Besides, the structure of prepositional phrase, presented in table 4.2, do not have equal frequencies, as certain structures of prepositional phrase for each documents, prepositional phrase structure like simple preposition and complex preposition, in which simple preposition is more frequent than others. In fact, according to the documents, prepositional phrases' structures vary in terms of their relative frequencies in the documents, as summarised in the following figure.

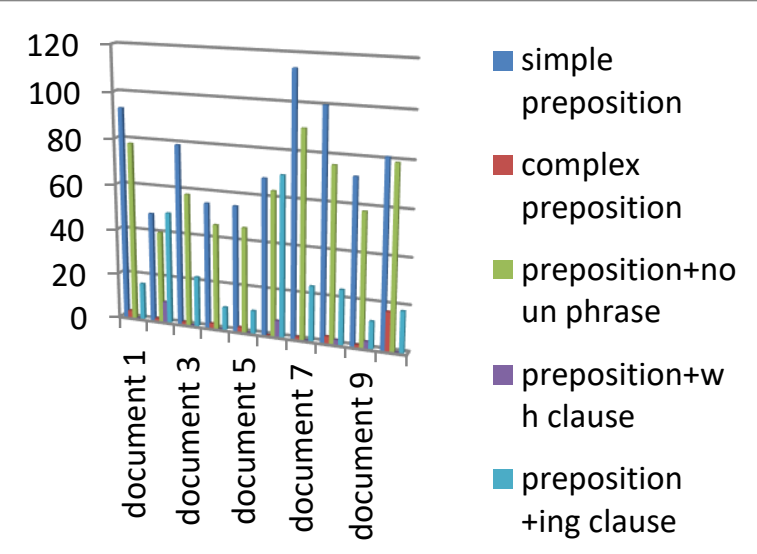

Figure 1 distribution of structure of prepositional phrase in each documents

Figure 1 reveals that while structure of prepositional phrase have almost the same distribution across the ten documents. For instance, largest concentrations of the structure prepositional phrase in which the structure of preposition simple prepositions are found in document 7, while the complex preposition seems to be more frequent in the document 10. Furthermore, for the structure of its noun phrase can be found in prepositional phrase (preposition +noun phrase) is mostly found in the document 7 , prepositional phrase (Preposition +wh clause) in the document 6, and prepositional phrase (preposition +ing clause) in the document 7 and 8.

These general distributions seem to reveal global as well as local frequencies, where "language...varies... according to the use (functional, or diatypic, variation). This functional variation takes the form of different registers and genres" (Halliday and Webster, 2009, p. 246). The purpose of the syntactic and semantic analyses is to explore the choices made in the document and to link them to the sentences at concluding paragraph of review of related literature chapter. Syntactically speaking, the moments of choice linked to the use of prepositions are related to the type of the preposition, the structure and the function of the whole phrase. The following section starts with simple and complex prepositions.

Furthermore, table 4.2 shows that 96 percent of the prepositional phrase structure in the Thesis are simple prepositions (765 cases), while only 3,65 percent are complex (29 cases). This result can be compared to the each documents of structure of prepositional phrase in each document (figure 4.1) where the structure of prepositional phrase 'simple preposition is classified among the most frequent prepositions in the Thesis. This shows a tendency of the writers to use simple preposition towards using prepositional phrase in stating their own ideas or statement at concluding paragraph in review of related literature chapter.

According to Downing and Locke (2006:536), preposition is divided into two groups. 1) Simple preposition. Preposition consists of a single prepositional particle. Here are the word lists as single prepositional particles.2) Complex preposition. Preposition which is combined of two or three prepositional particle. Based on the findings, all of the structures of this theory has stated in all of the documents. It means that all of the all the writers used prepositional phrase almost in all of concluding paragraph at review of related literature chapter on the Thesis. Besides, Carter and McCarthy (2006:251) gave "a list of more than 50 common simple prepositions". They argue that the writers took more than one kind of structure of prepositional phrase in writing, special care to contextualize the research area rather than establishing other moves. In the matter of this fact, the repetition of move 1 in the introduction investigated seems to disobey the basic structure of cars model.

Moreover, the second structure of prepositional phrase is its noun phrase structure. Noun phrases are the most frequent prepositional complements, according to different grammarians (Biber et al., 2007, Quirk et al., 2005). Biber et al. (2007) maintain that "the typical prepositional phrase may indeed be viewed as a noun phrase extended by a link showing its relationship to surrounding structures" (p. 103). A noun phrase is a group of words formed around a nucleus, which is the noun. The other elements namely the determiner, the premodifier and the postmodifier are optional. This makes NPs classified into simple or complex, depending on the additional components they comprise.

Furthermore, it was found that indicator for structure of prepositional phrase that has structured of its noun phrase S. 1.b (c) Preposition+ ing caluse. It is stated recurrently in almost all of the documents. It is repeated either in series of concluding paragraph for more than 5 prepositional phrase in a paragraph. It found that all of the writers used both of these structure on their concluding paragraph in the review of related 
literature chapter. The writers used prepositional phrase in expressing their opinion or when they restate the previous studies or theory and then replace with their own statement in which they used prepositional phrase as the part of their sentences in the concluding paragraph.

\section{CONCLUSIONS}

Based on the results of the data analysis and research findings that were conducted to structure of prepositional phrase that used in students' Thesis, it can be concluded that establishing the structure of prepositional phrase (S.1) has already been stated in all of the documents analyzed. It was found that from all 10 documents found of structure of prepositional phrase in their review of related literature on their Thesis. This indicator is established two steps; they are Step 1.a (structure of preposition) and Step 1.b (structure of its noun phrase). The data show that almost all of the writer's state Step 1.a and Step 1.b, however, only one of them who does not find complex preposition in the document. Thus, it can be said that almost all of the documents' is written by providing the writers' statement by stating prepositional phrase structure. The data shown that the writer tend to use simple preposition S.1a (a), largely more than complex preposition S.1a (b). Besides, for the noun phrase structure in prepositional phrase, it found that all of the structure of its noun phrase are found in all of the document although there are some of documents that do not find the structure of its noun phrase S. 1.b (b) preposition+ Wh clause.

\section{ACKNOWLEDGMENTS}

In accomplishing this thesis, there were great people who have contributed to this research. My deepest appreciation goes to my advisors Prof. Dr. Hermawati Syarif, M. hum and Dr. Refnaldi, M.Litt who have given valuable ideas, guidance, correction, suggestion, beneficial opinion and encouragement in the process of accomplishing this thesis. It is a pleasure to pay tribute also to my contributors, Prof. Dr. Jufrizal, M.Hum., Desvalini Anwar, S.S, M.Hum, Ph.D. for their suggestions, comments, time, contribution of thoughts and ideas toward the development and accomplishment of this thesis.

\section{REFERENCES}

[1] Biber, D.; Johansson, S.; Leech, G.; Conrad, S.; Finegan, E. (2007). Longman Grammar of Spoken and Written English. Pearson education limited. Sixth impression.

[2] Brown, H. D. 2001. Teaching by principles: an Integrative Approach to Language Pedagogy.New York: Addison Wesley Longman.
[3] Carter, R., McCarthy, M. (2006). Cambridge Grammar of English: A Comprehensive Guide: Spoken and Written English Grammar and Usage. Cambridge University Press.

[4] Cindy, L.Vitto. 2006. Grammar by DiagramSecond Edition: Understanding English Grammar Through Traditional Sentence Diagraming. New York:Broadview Press

[5] Downing and Locke. 2006.English Grammar A UniversityCourse.2nd Edition. New York: Routledge.

[6] Gay, L. R. 2009. Educational Research: Competencies for Analysis and Applications. New Jersey: Pearson Education, Inc.

[7] Halliday, M.A.K. (2005). Computational and Quantitative Studies. London and New York: Continuum.

[8] Halliday, M.A.K. and Webster, J. J. (2009) Continuum Companion to Systemic Functional Linguistics. London and New York: Continuum.

[9] Halliday, M.A.K. \& Matthiessen, C.M.I.M. (2014). An Introduction to Functional Grammar. Fourth Edition London: Edward Arnold.

[10] Quirk and Greenbaum. 1973. A University Grammar of English. London:Longman, Inc.

[11] Quirk, R., S. Greenbaum, G. Leech, and J. Svartvik (1985). A Comprehensive Grammar of the English Language. London: Longman.

[12] Quirk, R. (1986). Words at Work, Lectures on Textual Structure. Singapore University Press, Kent Ridge, Singapore.

[13] Quirk, R., S. Greenbaum, G. Leech, and J. Svartvik (2005). A Comprehensive Grammar of the English Language. London: Longman.

[14] Richards, J.C. \& Renandya, W.A. (Eds). (2002). Methodology In Language Teaching, An Anthology of Current Practice. New York: Cambridge University Press.

[15] Richards, J.C., \& Schmidt, W.R. (2010). Longman Dictionary of Language Teaching and Applied Linguistics. Rout ledge: Pearson Longman. 